\title{
IUGR in the Absence of Postnatal "Catch-Up" Growth Leads to Improved Whole Body Insulin Sensitivity in Rat Offspring
}

\author{
KYUNGJOON LIM, JAMES A. ARMITAGE, ANETA STEFANIDIS, BRIAN J. OLDFIELD, AND MARY JANE BLACK
}

Department of Anatomy and Developmental Biology [K.L., J.A.A., M.J.B.], Department of Physiology [A.S., B.J.O.], Monash University, Clayton, Victoria 3800, Australia

\begin{abstract}
A suboptimal in utero environment leads to fetal adaptations to ensure short-term survival but in the long-term may lead to disease when the postnatal growth does not reflect that in utero. This study examined the effect of IUGR on whole body insulin sensitivity and metabolic activity in adult rats. Female Wistar-Kyoto rats were fed either a normal protein diet (NPD 20\% casein) or a low protein diet (LPD; $8.7 \%$ casein) during pregnancy and $2 \mathrm{wk}$ of lactation. In offspring at $32 \mathrm{wk}$ of age, indirect calorimetry and dual energy x-ray absorptiometry (DEXA) were performed to assess metabolic activity and body composition. Insulin sensitivity was assessed using a euglycemic-hyperinsulinemic clamp. At $3 \mathrm{~d}$ of age, male and female LPD offspring were 23 and $27 \%$ smaller than controls, respectively. They remained significantly smaller throughout the experimental period $(\sim 10 \%$ smaller at $32 \mathrm{wk})$. Importantly, there was increased insulin sensitivity in LPD offspring (47\% increase in males and $38 \%$ increase in females); pancreatic insulin content was normal. Body composition, $\mathrm{O}_{2}$ consumption, respiratory exchange ratio (RER), and locomotor activity were not different to controls. These findings suggest that in the absence of "catch-up" growth IUGR programs for improved insulin sensitivity. (Pediatr Res 70: 339-344, 2011)
\end{abstract}

$\mathrm{O}$ ver recent years, there has been an escalation in the incidence of metabolic syndrome and type 2 diabetes within the community, and this has been linked to a mismatch in prenatal and postnatal growth (1-3). In this regard, many epidemiological and experimental studies support the hypothesis that a suboptimal in utero environment leads to fetal adaptations to ensure short-term survival but, in turn, lead to long-term disease risk when the postnatal environment does not reflect that in utero (2-4). In addition, IUGR leads to a reduction in prenatal growth and altered ontogeny of major organs, which may also contribute to long-term disease risk (5-8). For example, IUGR, because of maternal protein restriction in rats has been shown to lead to a reduced number of cardiomyocytes in the heart (6), reduced nephron endowment in the kidney (7), and reduced $\beta$-cell proliferation and islet size in the pancreas (8).

Hence, it is likely that altered programming of glucose metabolism coupled with direct reductions in pancreatic islet $\beta$ cells contribute to the development of metabolic syndrome and type 2 diabetes in infants that were growth restricted in

Received January 4, 2011; accepted May 2, 2011

Correspondence: M. Jane Black, Ph.D., Department of Anatomy \& Developmental Biology, Level 3 Building 76 Monash University, Victoria 3800, Australia; e-mail: jane.black@monash.edu

Supported by a National Health and Medical Research Postgraduate scholarship whilst undertaking this study [K.L.]. utero, particularly when the postnatal growth trajectory is inappropriately higher than that in utero (9). Although there is substantial evidence to support this hypothesis, whether IUGR can program for improved postnatal glucose metabolism in the absence of "catch-up" growth has been relatively unexplored, and it is imperative that this alternative be rigorously tested. Importantly, in this regard, in our laboratory, we have a model of maternal protein restriction in Wistar Kyoto (WKY) rats where the IUGR offspring remain smaller throughout life when compared with nongrowth restricted offspring; these offspring also remain normotensive (7). The Thrifty Phenotype hypothesis $(4,10,11)$ predicts that coronary heart disease, type 2 diabetes, stroke, and hypertension manifest because undernutrition during fetal life and infancy initiates altered structure, but disease only manifests when offspring demonstrate catch-up growth in adulthood. We propose that because our IUGR offspring show postnatal growth appropriate to body composition they will be programmed for improved glucose regulation in adulthood as long as catch-up growth does not occur. In our model, the dams are fed a low protein diet (LPD) for 2 wk before pregnancy, throughout pregnancy, and for $2 \mathrm{wk}$ in lactation. This maternal dietary regime differs from the protocol of many laboratories where the dams are only fed the LPD during pregnancy. This may account for the persistent reduced growth and normotension that we observe in the offspring. Our specific aims were to determine in adult rat offspring whether restricted growth in utero followed by persistently low body growth throughout life leads to differences in food intake, whole body insulin sensitivity, energy expenditure, and locomotor activity.

\section{METHODS}

Animals and diet treatment. WKY rat dams were fed either a LPD $(8.7 \%$ casein) or a normal protein diet (NPD; 20\% casein) for 2 wk before mating, during pregnancy, and for a further 2 wk after birth (12). The nutrient content of the semipurified diets (vitamins, minerals, methionine, and oils) was equivalent, except the starch, which was manipulated to ensure that the diets were close to isocaloric (Glen Forrest Stockfeeders, Glen Forrest, Western Australia) (12). Diet intake was monitored daily until weaning at $4 \mathrm{wk}$ of age. To prevent stress to the dams, the pups were not handled until $3 \mathrm{~d}$ after birth. At $3 \mathrm{~d}$ of age, all litters were culled to 8 pups per dam (average litter size was

Abbreviations: BWT, body weight; D, diet, used as a main effect in ANOVA model; $\mathbf{D} \times \mathbf{G}$, diet by gender interaction term used in ANOVA model; DEXA, dual energy x-ray absorptiometry; G, gender, used as an interaction term in ANOVA model; ISI, insulin sensitivity index; LPD, low protein diet; NPD, normal protein diet; RER, respiratory exchange ratio 
between 10 and 14 per dam) and the remaining offspring allowed to grow to 32 wk of age. Seven male and female offspring per group (1 male and 1 female derived randomly per litter) were used. At weaning, the rats were housed at two rats per cage until 24 wk of age. From 24 wk of age, animals were housed individually for measurement of dietary intake. At $32 \mathrm{wk}$ of age, the rats were perfusion fixed (12). The pancreas and visceral fat (epididymal and intra-abdominal) were excised and weighed. All animal experiments were approved by the Monash University Biochemistry, Anatomy and Microbiology Animal Ethics Committee, and treatment and care of the animals conformed to the Australian code of practice for the care and use of animals for scientific purposes.

Growth trajectories. From $3 \mathrm{~d}$ after birth to $32 \mathrm{wk}$ of age, body weight (BWT), abdominal girth, head length, head width, and hind leg length were measured weekly (13).

Blood pressure. Tail-cuff systolic blood pressure was measured in prewarmed restrained rats (NPD and LPD offspring) from 24 to 32 wk of age. The blood pressure measurements were performed in triplicate twice weekly.

Indirect calorimetry. At 31 wk of age, $\mathrm{O}_{2}$ consumption, RER, energy expenditure, and general locomotor activity was assessed using indirect calorimetry. The calorimetry system consists of custom-made cages in which the sample air is transferred to a control unit that contains specialized $\mathrm{O}_{2}$ and $\mathrm{CO}_{2}$ sensors that determine changes in air concentrations of $\mathrm{O}_{2}$ and $\mathrm{CO}_{2}(\mathrm{TSE}$ Systems, Bad Homburg, Germany). All rats were monitored in the cages (one rat per cage) for at least $72 \mathrm{~h}$ including a 24-h acclimatization period. $\mathrm{O}_{2}$ consumption $\left(\mathrm{VO}_{2}\right)$ and $\mathrm{CO}_{2}$ production $\left(\mathrm{VCO}_{2}\right)$ were measured every $30 \mathrm{~min}$ for $3 \mathrm{~min} / \mathrm{cage}$ and recorded using specialized software. RER was calculated as the quotient of $\mathrm{VCO}_{2} / \mathrm{VO}_{2}$, with a value of 1 representing $100 \%$ carbohydrate oxidation and 0.7 representing $100 \%$ fat oxidation. In addition, cage tops were equipped with infrared sensors (TSE InfraMot; TSE Systems) to assess general locomotor activity of the animals, measured as arbitrary "InfraMot units."

Dual energy $x$-ray absorptiometry-assessment of body composition. At $32 \mathrm{wk}$ of age, rats were anesthetized using isoflurane; lean muscle mass, bone mineral content, and total \% of fat were determined by scanning with an Hologic Discovery A-QDR series bone densitometer (Hologic, Inc., MA).

Pancreatic insulin concentration. Pancreatic (tissue extraction) insulin levels were measured by radioimmunoassay (ProSearch International Australia Pty Ltd, Victoria, Australia) using a Linco Research radioimmunoassay kit for rat insulin.

Whole body insulin sensitivity. Insulin sensitivity was assessed in NPD and LPD offspring at $32 \mathrm{wk}$ of age using a euglycemic-hyperinsulinemic clamp. Rats were anesthetized, and catheters were inserted into the left femoral vein, right femoral vein, and right femoral artery. A priming dose of insulin (Actrapid $10 \mu \mathrm{IU} / \mathrm{kg} / \mathrm{min}$; Novo Nordisk, Gentofte, Denmark) was infused in the left femoral vein at a constant rate $(31.66 \mu \mathrm{L} / \mathrm{min}$; rate determined in pilot study). A variable glucose infusion was administered through the right femoral vein $1 \mathrm{~min}$ after the insulin infusion started. The infusion rate of the priming dose of glucose was determined through an initial pilot study. Blood glucose was measured every 5 min using a TrueTrack smart system blood glucose monitor (Home Diagnostics, Inc., Fort Lauderdale, FL), and the glucose infusion rate was adjusted to maintain euglycemia. A steady state was attained after $\sim 30 \mathrm{~min}$ and was maintained for an additional $30 \mathrm{~min}$. The insulin sensitivity index (ISI) was then calculated according to Damas et al. (14).

$$
\text { ISI }=\frac{\text { Steady state glucose infusion rate }\left(\mathrm{mg} \cdot \mathrm{kg} \cdot{ }^{-1} \mathrm{~min}^{-1}\right)}{\text { Steady state plasma insulin infusion rate }\left(\mathrm{mU} \cdot \mathrm{kg} \cdot{ }^{-1} \mathrm{~min}^{-1}\right)}
$$

Statistical analysis. All data are expressed as mean \pm SEM (SEM). Data were statistically analyzed using GraphPad Prism (version 5.00; GraphPad Software, SanDiego, CA, USA). A two-way ANOVA was applied to data at 32 wk of age; factors were represented as maternal diet ( $p_{\mathrm{D}}$; LPD or NPD), gender $\left(p_{\mathrm{G}}\right.$; male or female), and their interaction $\left(p_{\mathrm{D} \times \mathrm{G}}\right)$. Statistical significance was accepted at the level of $p<0.05$. Changes in BWT, head length, abdominal girth, head width, hind limb length, blood pressure, $\mathrm{O}_{2}$ consumption, RER, and energy expenditure over time were analyzed using a repeated measures two-way ANOVA.

\section{RESULTS}

Growth trajectories. BWT was significantly reduced at $3 \mathrm{~d}$ of age in LPD offspring compared with NPD offspring (23\% reduction in males and $28 \%$ reduction in females; Table 1).

Postnatal growth in LPD and NPD offspring from $1 \mathrm{wk}$ to $32 \mathrm{wk}$ of age is depicted in Figure 1A. At $32 \mathrm{wk}$ of age, BWT of LPD offspring remained significantly reduced compared with NPD offspring in both male and female offspring $(9 \%$ lower in male, $p<0.05$ and $10 \%$ lower in female offspring, $p<0.05$; Fig. 1A). LPD offspring also exhibited a significantly decreased growth in head length (Fig. $1 B, p<0.05$ ), abdominal girth (Fig. $1 C, p<0.05$ ), and hind limb length (Fig. $1 D, p<0.05$ ) but no difference in head width (Fig. 1E) throughout the experimental period.

DEXA analysis: body composition. DEXA scanning showed no differences in relative lean muscle mass (Fig. 2A) and total \% of body fat (Fig. $2 B$ ) between LPD offspring and NPD offspring or in male offspring versus female offspring. Female offspring exhibited an increased relative bone mineral

Table 1. BWT, pancreas weight, and visceral fat pad weight in NPD and LPD offspring at 32 wk of age

\begin{tabular}{|c|c|c|c|c|c|}
\hline & $\begin{array}{l}\text { NPD (male) } \\
\quad(n=7)\end{array}$ & $\begin{array}{l}\text { NPD (female) } \\
\quad(n=7)\end{array}$ & $\begin{array}{l}\text { LPD (male) } \\
\quad(n=7)\end{array}$ & $\begin{array}{l}\text { LPD (female) } \\
\quad(n=7)\end{array}$ & $p$ \\
\hline BWT at $3 \mathrm{~d}$ of age $(\mathrm{g})$ & $5.77 \pm 0.17$ & $5.90 \pm 0.13$ & $4.44 \pm 0.13$ & $4.28 \pm 0.13$ & $\begin{array}{l}p_{\mathrm{D}}=0.0001 * \\
p_{\mathrm{G}}=0.93 \\
p_{\mathrm{D} \times \mathrm{G}}=0.33\end{array}$ \\
\hline BWT at 32 wk of age $(\mathrm{g})$ & $462 \pm 8$ & $262 \pm 4$ & $422 \pm 8$ & $236 \pm 6$ & $\begin{array}{l}p_{\mathrm{D}}=0.0002 * \\
p_{\mathrm{G}}<0.0001 * \\
p_{\mathrm{D} \times \mathrm{G}}=0.38\end{array}$ \\
\hline Pancreas weight (mg) & $636 \pm 30$ & $576 \pm 20$ & $676 \pm 90$ & $540 \pm 50$ & $\begin{array}{l}p_{\mathrm{D}}=0.96 \\
p_{\mathrm{G}}=0.06 \\
p_{\mathrm{D} \times \mathrm{G}}=0.45\end{array}$ \\
\hline Visceral fat pad weight (mg) & $16448 \pm 1318$ & $10501 \pm 719$ & $16136 \pm 976$ & $8525 \pm 539$ & $\begin{array}{l}p_{\mathrm{D}}=0.27 \\
p_{\mathrm{G}}<0.0001 *\end{array}$ \\
\hline Pancreas weight: BWT (mg/g) & $1.3 \pm 0.1$ & $2.1 \pm 0.1$ & $1.6 \pm 0.2$ & $2.2 \pm 0.1$ & $\begin{array}{l}p_{\mathrm{D} \times \mathrm{G}}=0.42 \\
p_{\mathrm{D}}=0.38 \\
p_{\mathrm{G}}=0.03^{*} \\
p_{\mathrm{D} \times \mathrm{G}}=0.66\end{array}$ \\
\hline Visceral fat pad weight: BWT (mg/g) & $36.6 \pm 0.03$ & $40.1 \pm 0.04$ & $38.2 \pm 0.02$ & $36.1 \pm 0.02$ & $\begin{array}{l}p_{\mathrm{D}}=0.45 \\
p_{\mathrm{G}}=0.39 \\
p_{\mathrm{D} \times \mathrm{G}}=0.14\end{array}$ \\
\hline
\end{tabular}

Data were analyzed by a two-way ANOVA with maternal diet (D: NPD or LPD), gender (G: male or female), and maternal diet $\times$ gender (D $\times$ G) interaction as factors.

$* p<0.05$. 

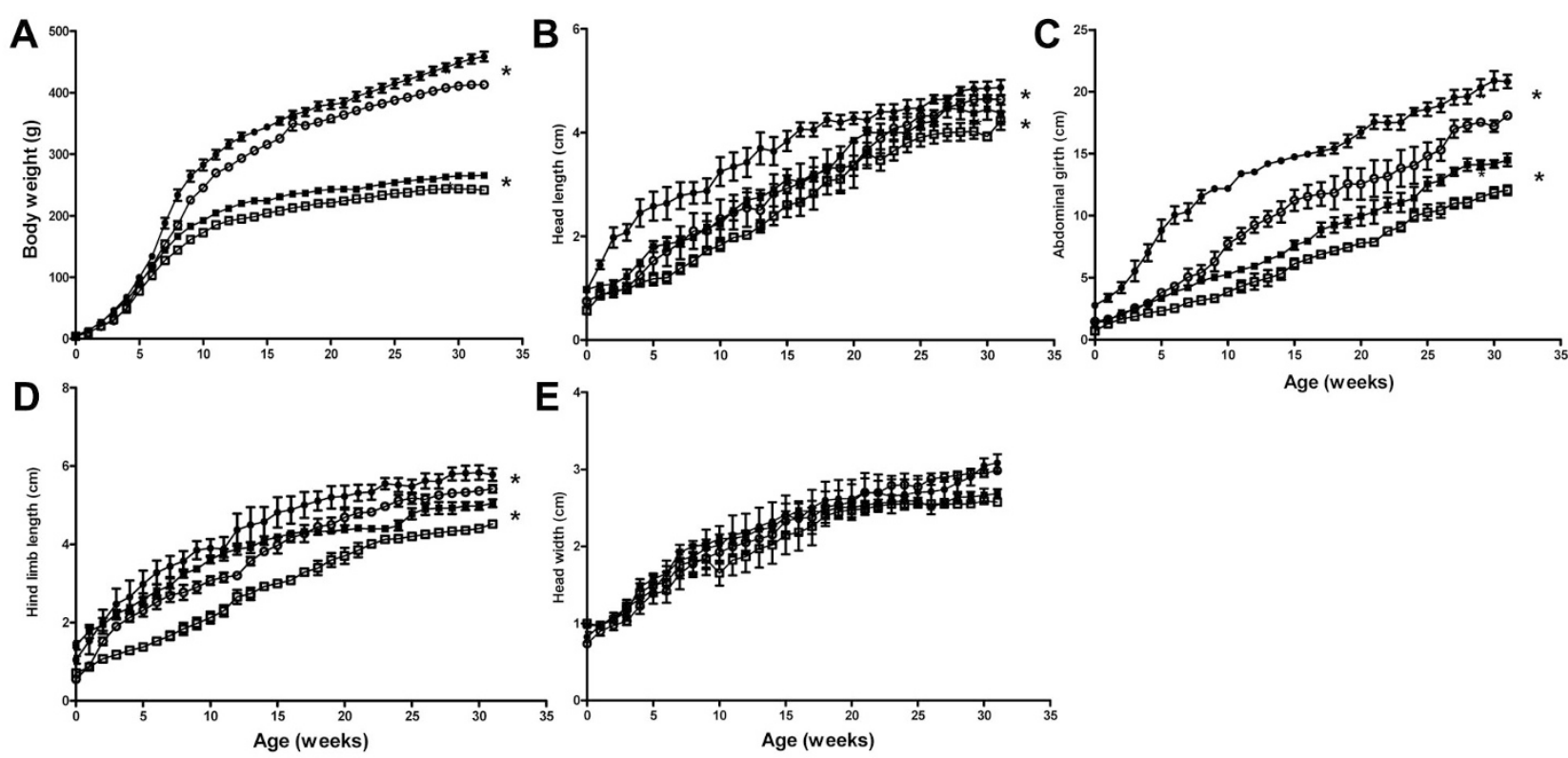

Figure 1. Postnatal measurements from 0 to 32 wk of age of $(A)$ BWT, $(B)$ head length, $(C)$ abdominal girth, $(D)$ hind limb length, and $(E)$ head width in NPD (male $\bullet, n=7$ and female $\square, n=7$ ) and LPD (male $\bigcirc, n=7$ and female $\square, n=7$ ) offspring. Data were analyzed by a repeated measures two-way ANOVA. $* p<0.05$. Error bars represent \pm SEM.
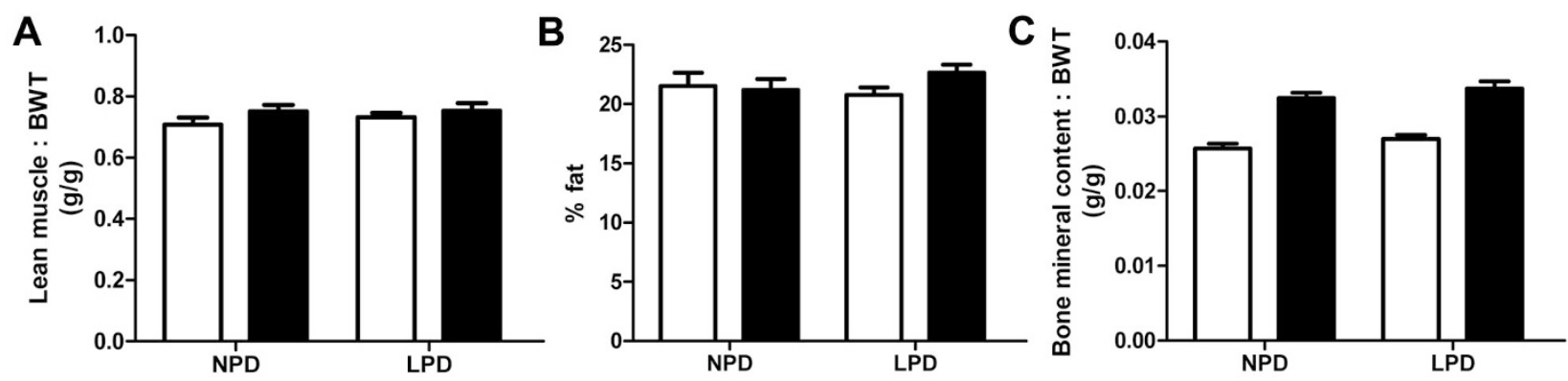

Figure 2. Body composition assessed by DEXA: $(A)$ lean muscle mass: BWT; $(B)$ total \% of fat; and $(C)$ relative bone mineral content: BWT (males: M $\square$; females: F D). Data were analyzed by a two-way ANOVA with maternal diet (D: NPD or LPD), gender (G; male or female) and maternal diet $\times$ gender (D $\times$ G) interaction as factors. There was a significant gender difference $\left(p_{\mathrm{G}}<0.001\right)$ in bone mineral content: BWT.

content compared with male offspring $\left(p_{\mathrm{G}}<0.001\right)$, but there was no difference between NPD and LPD offspring (Fig. $2 C$ ).

Dietary intake. When food intake was measured in adulthood (from 24 to $32 \mathrm{wk}$ of age), LPD offspring consumed significantly less $(p<0.0001)$ compared with NPD offspring in both males and females. However, when food intake was corrected to lean muscle mass, there was no significant difference between LPD and NPD offspring.

Indirect calorimetry. Over a 48-h experimental period, there was no difference in energy expenditure between adult NPD and LPD offspring (Fig. 3A). Overall, females exhibited a greater energy expenditure $(p<0.0001)$ compared with males. Female offspring showed significantly greater $\mathrm{O}_{2}$ consumption per gram of BWT $(p<0.0001)$, whereas there was no difference between LPD offspring and NPD offspring in $\mathrm{O}_{2}$ consumption (Fig. 3B). There were no significant differences in RER (Fig. 3C) and locomotor activity (Fig. 3D) between NPD offspring and LPD offspring. However, locomotor activity was greater $(p<0.0001)$ in female offspring compared with male offspring (Fig. 3D).
Blood pressure. Blood pressure remained relatively constant throughout the measurement period (24 to $32 \mathrm{wk}$ ) in all rats (Fig. 4). There was no significant effect of maternal protein restriction or gender on blood pressure.

Whole body insulin sensitivity. At $32 \mathrm{wk}$ of age, whole body ISI was significantly greater in LPD offspring compared with NPD offspring (70\% increase, $p_{\mathrm{D}}<0.0001$; Fig. 5); ISI per lean body mass was also significantly increased $\left(p_{\mathrm{D}}<\right.$ 0.0001 ). There was also a significantly greater ISI in female offspring; females exhibited a $39 \%$ increase $\left(p_{\mathrm{G}}=0.0046\right)$ compared with males. The highest whole body ISI was observed in female LPD offspring.

Pancreatic insulin levels. At 32 wk of age, there was no significant difference in pancreatic insulin levels between NPD and LPD offspring (males: $0.119 \pm 0.013 \mathrm{mg} / \mathrm{g}$ and $0.096 \pm 0.023 \mathrm{mg} / \mathrm{g}$, respectively, and females: $0.086 \pm 0.01$ $\mathrm{mg} / \mathrm{g}$ and $0.083 \pm 0.004 \mathrm{mg} / \mathrm{g}$, respectively).

Pancreas and visceral fat weight. At necropsy, there was no difference in absolute pancreas weight or relative pancreas weight or visceral fat (epididymal and intra-abdominal) 

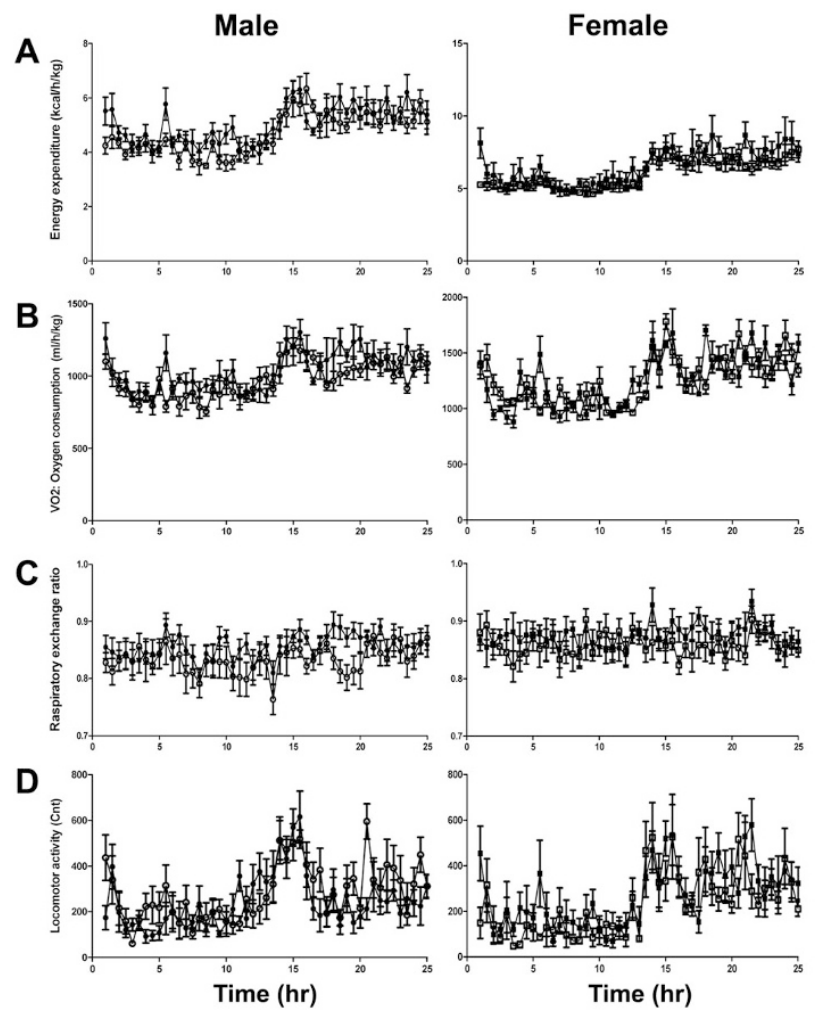

Figure 3. Indirect calorimetry measurements of $(A)$ energy expenditure, $(B)$ $\mathrm{O}_{2}$ consumption, $(C)$ RER, and $(D)$ locomotor activity in NPD (male $\mathbf{O}, n=$ 7 and female $\square, n=7$ ) and LPD (male $\bigcirc, n=7$ and female $\square, n=7$ ) offspring at $31 \mathrm{wk}$ of age. Data were analyzed by a repeated two-way ANOVA. There were no statistical differences between NPD and LPD offspring. Error bars represent \pm SEM.

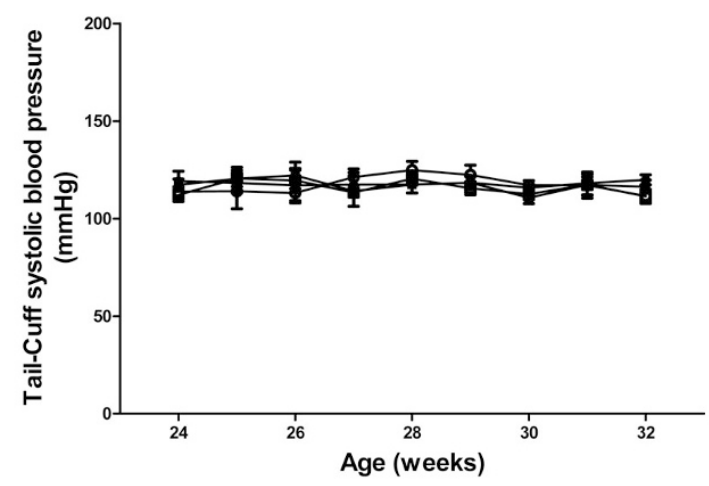

Figure 4. Tail cuff systolic blood pressure measured from 24 to $32 \mathrm{wk}$ of age in NPD (male $\bullet, n=7$ and female $\boldsymbol{\square}, n=7$ ) and LPD (male $\bigcirc, n=7$ and female $\square, n=7$ ) offspring. Data were analyzed by a repeated two-way ANOVA. There were no statistical differences between NPD and LPD offspring. Error bars represent \pm SEM.

weight between LPD offspring and NPD offspring. When corrected to BWT, there was a significant increase in relative pancreatic weight in female offspring $\left(p_{\mathrm{G}}=0.03\right)$ compared with male offspring (Table 1).

\section{DISCUSSION}

In this study, we clearly demonstrate improved whole body insulin sensitivity in rat offspring that were growth restricted in utero and whose growth trajectory remained attenuated in

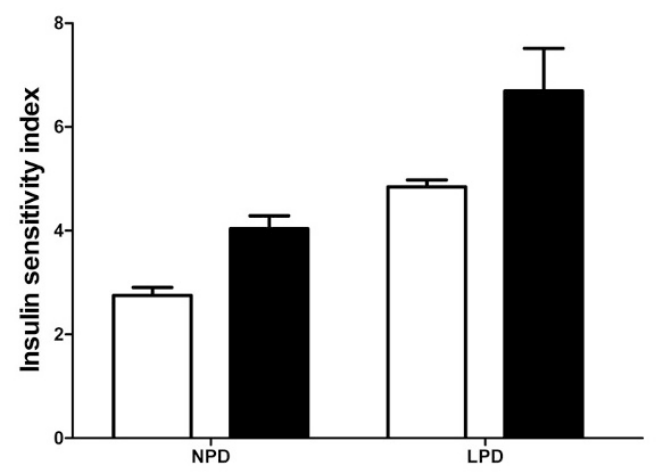

Figure 5. Bar graph depicting ISI (a measure of whole body insulin sensitivity) in male (M: $\square$ ) and female (F: $\square)$ NPD and LPD offspring ( $n=7$ in all groups) at 32 wk of age. Data were analyzed by two-way ANOVA with maternal diet (D: NPD or LPD), gender (G; male or female) and maternal diet $\times$ gender $(\mathrm{D} \times \mathrm{G})$ interaction as factors. There was a significant maternal diet effect $\left(p_{\mathrm{D}}=0.0001\right)$ and significant gender effect $\left(p_{\mathrm{G}}=0.0043\right)$.

adulthood. Thirty-two-week-old offspring of protein restricted rats were of lower BWT compared with age-matched controls and DEXA body composition analysis indicated that fat and lean muscle mass were proportional to BWT; pancreatic insulin content was normal. Caloric intake was lower in offspring of protein restricted rats compared with controls but was appropriate for BWT. To determine whether energy expenditure and metabolic parameters were affected by exposure to a protein restricted diet during development, we carried out indirect calorimetry. Analysis showed no differences in oxygen consumption, RER, and energy expenditure between IUGR and non-IUGR offspring. Hence, our findings of improved insulin sensitivity in the absence of catch-up in body growth clearly supports the concept of programming for improved glucose regulation in adulthood when the postnatal growth trajectory resembles that in utero. In accordance with previously published studies, there were no differences in blood pressure in the IUGR and non-IUGR offspring over the experimental period (7).

Appropriate postnatal growth trajectory to that predicted in utero. In the present study, the LPD offspring were $9 \%$ lighter in males and 10\% lighter in females compared with controls at $3 \mathrm{~d}$ of age (the first time point when BWT was measured). Comprehensive growth measurements in the experimental period after birth ( $3 \mathrm{~d}$ to $32 \mathrm{wk}$ ) clearly demonstrated an attenuated postnatal body growth in the LPD offspring; the reduced BWT were accompanied by proportional reductions in abdominal girth, hind limb length, and head length. Thus, there is no evidence for asymmetric growth in these offspring. Growth trajectories in IUGR offspring did not show evidence of catch-up growth nor was there evidence of altered body composition in adulthood when organ and fat pad mass were determined. Because measurement of adiposity by dissecting and weighing fat pads does not take into account differences in intramuscular or s.c. fat deposition, we, therefore, also measured whole body composition by DEXA. Whole body DEXA offered no evidence for increased deposition of body fat in the IUGR offspring. These findings are contrary to the findings of other studies where altered pro- 
gramming of body fat composition has been described in IUGR offspring; however, this usually occurs when there is catch-up in body growth $(15,16)$.

IUGR in the absence of postnatal catch-up in growth appears to program for improved insulin sensitivity in adulthood. As initially hypothesized, we have observed increased insulin sensitivity in adult offspring that had been growth restricted in utero and whose growth trajectory after birth remained significantly attenuated when compared with nongrowth-restricted offspring. Our findings support previous studies where in young adulthood, IUGR offspring have a significantly better glucose tolerance and insulin sensitivity than controls $(17,18)$ when their BWT is maintained on a lower growth trajectory after birth. Importantly, the programming of increased insulin sensitivity in the IUGR offspring in adulthood was accompanied by normal carbohydrate metabolism, normal body composition, and attenuation in daily food intake in the adult offspring. Indeed, a mismatch in prenatal and postnatal growth is thought to be a major contributing factor to the impaired glucose metabolism often observed in IUGR subjects, with epidemiological studies demonstrating that the highest risk of metabolic syndrome occurs when IUGR is followed by catch-up in growth after birth (19-21).

In our model of maternal protein restriction, the offspring are not only growth restricted in utero but they remain smaller throughout life. The lack of catch-up growth is not what the "thrifty phenotype" hypothesis predicts (4); our offspring were IUGR because of a reduction in maternal protein availability but when weaned they were allowed ad libitum access to a NPD, which theoretically represents an increased plane of nutrition. Based on the "thrifty phenotype" hypothesis, catch-up growth, accumulation of body fat and insulin resistance should subsequently ensue. However, in our study, because IUGR offspring did not demonstrate catch-up in body growth, the findings of improved whole body insulin sensitivity is as predicted.

At this stage, we cannot identify the mechanisms underlying the persistent reduction in body growth in LPD offspring, however, it is likely that the IGFs (IGF-I and IGF-II) may be involved in the long-term programming of reduced body growth $(22,23)$ and thus enhancing insulin sensitivity.

Importantly, our dietary regime of maternal protein restriction differs from many other laboratories in that the rat dams were administered the LPD for 2 wk before mating, throughout pregnancy and for 2 wk during lactation $(6,7,12)$. Indeed, there have been a number of recent studies demonstrating the importance of not only the intrauterine environment but also the periconceptional and lactational environment in determining the long-term growth profile of the offspring (24-27). Certainly, it is conceivable that prolonged suboptimal nutrition from the periconceptional period until $2 \mathrm{wk}$ during lactation will have a different programming effect on body growth when compared with suboptimal nutrition during pregnancy only.

In the present study, there was improved insulin sensitivity in females compared with males in both control and LPD offspring. These findings are in accordance with previously published findings of lower postabsorptive insulin levels in females compared with males $(26,28)$, suggesting that female rats are intrinsically more sensitive to insulin than males. It is thought that the nutritional sensitivity in males may relate to faster growth of tissues in males and hence more critical nutritional needs (29).

Metabolism and energy consumption. It was considered likely in the undertaking of these studies that the improved insulin sensitivity and lack of catch-up in growth in our LPD offspring would be associated with an increased metabolic rate or a shift in the balance between carbohydrate and fat metabolism. To the contrary, however, using highly sensitive indirect calorimetric techniques we found no differences in $\mathrm{O}_{2}$ consumption, energy expenditure, or RER between the NPD and LPD offspring, thus demonstrating that the oxidative phosphorylation and $\beta$-oxidative pathways governing glucose and fat metabolism were normal in our IUGR offspring. Given that pancreatic insulin content was also normal, by a process of elimination, we therefore speculate that the observed increased insulin sensitivity in the IUGR offspring is because of alterations in insulin signaling as has been suggested by Ozanne et al. (30,31). Further studies in isolated pancreatic islet $\beta$ cells are required to confirm this. An alternative possibility is that the consumption of the LPD by lactating dams in the first $2 \mathrm{wk}$ after birth resulted in a change in the postnatal leptin surge that occurs in rodents and is responsible for maturation of appetite circuits. Indeed, Vickers et al. (32) show that the phenotype in offspring of semistarved rats can be normalized by administering leptin to pups in early postnatal life and Kirk et al. (33) showed an exaggerated postnatal leptin surge in offspring of obese mice.

Programming of appetite. In the present study, food intake was significantly reduced in the LPD offspring in adulthood, however, when adjusted to BWT, this was not different to controls; whether the food intake was a corollary of body size or whether body size was a corollary of food intake is uncertain. Previous findings suggest that the early postnatal period is crucial in the programming of long-term appetite $(26,34,35)$ thus highlighting the importance of the diet of the mother during lactation on the subsequent growth trajectory of the offspring. Therefore, since our LPD offspring were exposed to maternal protein restriction for $2 \mathrm{wk}$ during lactation (the first 2 wk postnatally), it is likely that the reduced postnatal appetite and attenuated growth trajectory was programmed in the early lactational period. Hence, restricting the diet 2 wk before mating, during pregnancy, and during $2 \mathrm{wk}$ of lactation may have programmed the appetite, which eventually prevented the loss of insulin sensitivity after neonatal life. Furthermore, this would account for the catch-up in growth often observed in other rat models of maternal protein restriction, where it is usual for the mothers to be placed onto normal laboratory chow at birth; this may initiate a shift in the early postnatal growth trajectory or alter the timing or peak of the postnatal leptin surge (36), which is thought to be critical in shaping the neural architecture of hypothalamic feeding circuitry (37). In future studies, analysis of leptin levels in our LPD offspring in the early postnatal period and later in adulthood would help to elucidate whether there is lactational programming of appetite. 
In conclusion, our findings clearly demonstrate that maternal protein restriction and/or IUGR can lead to the programming of improved postnatal whole body insulin sensitivity when postnatal growth is similar to that in utero. Importantly, lack of hypertension in our animals may also be due to the absence of catch-up growth in IUGR rat offspring. The findings thus highlight the importance of maintaining a similar growth trajectory after birth to that in utero.

\section{REFERENCES}

1. Armitage JA, Khan IY, Taylor PD, Nathanielsz PW, Poston L 2004 Developmenta programming of the metabolic syndrome by maternal nutritional imbalance: how strong is the evidence from experimental models in mammals? J Physiol 561:355377

2. Varvarigou AA 2010 Intrauterine growth restriction as a potential risk factor for disease onset in adulthood. J Pediatr Endocrinol Metab 23:215-224

3. Halliday HL 2009 Neonatal management and long-term sequelae. Best Pract Res Clin Obstet Gynaecol 23:871-880

4. Hales CN, Barker DJ 2001 The thrifty phenotype hypothesis. Br Med Bull 60:5-20

5. Lipsett J, Tamblyn M, Madigan K, Roberts P, Cool JC, Runciman SI, McMillen IC, Robinson J, Owens JA 2006 Restricted fetal growth and lung development: a morphometric analysis of pulmonary structure. Pediatr Pulmonol 41:1138-1145

6. Corstius HB, Zimanyi MA, Maka N, Herath T, Thomas W, van der Laarse A Wreford NG, Black MJ 2005 Effect of intrauterine growth restriction on the number of cardiomyocytes in rat hearts. Pediatr Res 57:796-800

7. Zimanyi MA, Denton KM, Forbes JM, Thallas-Bonke V, Thomas MC, Poon F, Black MJ 2006 A developmental nephron deficit in rats is associated with increased susceptibility to a secondary renal injury due to advanced glycation end-products. Diabetologia 49:801-810

8. Snoeck A, Remacle C, Reusens B, Hoet JJ 1990 Effect of a low protein diet during pregnancy on the fetal rat endocrine pancreas. Biol Neonate 57:107-118

9. Hales CN, Desai M, Ozanne SE, Crowther NJ 1996 Fishing in the stream of diabetes: from measuring insulin to the control of fetal organogenesis. Biochem Soc Trans 24:341-350

10. Barker DJ, Eriksson JG, Forsen T, Osmond C 2002 Fetal origins of adult disease: strength of effects and biological basis. Int J Epidemiol 31:1235-1239

11. Gluckman PD, Hanson MA 2006 The consequences of being born small-an adaptive perspective. Horm Res 65:5-14

12. Lim K, Zimanyi MA, Black MJ 2006 Effect of maternal protein restriction in rats on cardiac fibrosis and capillarization in adulthood. Pediatr Res 60:83-87

13. Watson RH, Broadhurst PL 1976 A factor analysis of body build in the rat. Am J Phys Anthropol 44:513-519

14. Damas J, Bourdon V, Lefebvre PJ 1999 Insulin sensitivity, clearance and release in kininogen-deficient rats. Exp Physiol 84:549-557

15. Bhasin KK, van Nas A, Martin LJ, Davis RC, Devaskar SU, Lusis AJ 2009 Maternal low-protein diet or hypercholesterolemia reduces circulating essential amino acids and leads to intrauterine growth restriction. Diabetes 58:559-566

16. Desai M, Gayle D, Babu J, Ross MG 2007 The timing of nutrient restriction during rat pregnancy/lactation alters metabolic syndrome phenotype. Am J Obstet Gynecol 196:555.e1-555.e7

17. Shepherd PR, Crowther NJ, Desai M, Hales CN, Ozanne SE 1997 Altered adipocyte properties in the offspring of protein malnourished rats. Br J Nutr 78:121-129
18. Ozanne SE, Wang CL, Coleman N, Smith GD 1996 Altered muscle insulin sensitivity in the male offspring of protein-malnourished rats. Am J Physiol 271:E1128-E1134

19. Ravelli AC, van der Meulen JH, Michels RP, Osmond C, Barker DJ, Hales CN, Bleker OP 1998 Glucose tolerance in adults after prenatal exposure to famine. Lancet 351:173-177

20. Phillips DI, McLeish R, Osmond C, Hales CN 1995 Fetal growth and insulin resistance in adult life: role of plasma triglyceride and non-esterified fatty acids. Diabet Med 12:796-801

21. Roseboom T, de Rooij S, Painter R 2006 The Dutch famine and its long-term consequences for adult health. Early Hum Dev 82:485-491

22. DeChiara TM, Efstratiadis A, Robertson EJ 1990 A growth-deficiency phenotype in heterozygous mice carrying an insulin-like growth factor II gene disrupted by targeting. Nature 345:78-80

23. Woods KA, Camacho-Hübner C, Savage MO, Clark AJ 1996 Intrauterine growth retardation and postnatal growth failure associated with deletion of the insulin-like growth factor I gene. N Engl J Med 335:1363-1367

24. MacLaughlin SM, Walker SK, Roberts CT, Kleemann DO, McMillen IC 2005 Periconceptional nutrition and the relationship between maternal body weight changes in the periconceptional period and feto-placental growth in the sheep. J Physiol 565:111-124

25. Joshi S, Garole V, Daware M, Girigosavi S, Rao S 2003 Maternal protein restriction before pregnancy affects vital organs of offspring in Wistar rats. Metabolism 52:13-18

26. Desai M, Babu J, Ross MG 2007 Programmed metabolic syndrome: prenatal undernutrition and post-weaning overnutrition. Am J Physiol Regul Integr Comp Physiol 293:R2306-R2314

27. Wlodek ME, Mibus A, Tan A, Siebel AL, Owens JA, Moritz KM 2007 Normal lactational environment restores nephron e ndowment and prevents hypertension after placental restriction in the rat. J Am Soc Nephrol 18:1688-1696

28. Sugden MC, Holness MJ 2002 Gender-specific programming of insulin secretion and action. J Endocrinol 175:757-767

29. Lucas A, Baker BA, Desai M, Hales CN 1996 Nutrition in pregnant or lactating rats programs lipid metabolism in the offspring. Br J Nutr 76:605-612

30. Ozanne SE, Jensen CB, Tingey KJ, Storgaard H, Madsbad S, Vaag AA 2005 Low birthweight is associated with specific changes in muscle insulin-signalling protein expression. Diabetologia 48:547-552

31. Ozanne SE, Olsen GS, Hansen LL, Tingey KJ, Nave BT, Wang CL, Hartil K, Petry CJ, Buckley AJ, Mosthaf-Seedorf L 2003 Early growth restriction leads to down regulation of protein kinase $\mathrm{C}$ zeta and insulin resistance in skeletal muscle. J Endocrinol 177:235-241

32. Vickers MH, Gluckman PD, Coveny AH, Hofman PL, Cutfield WS, Gertler A, Breier BH, Harris M 2005 Neonatal leptin treatment reverses developmental programming. Endocrinology 146:4211-4216

33. Kirk SL, Samuelsson AM, Argenton M, Dhonye H, Kalamatianos T, Poston L, Taylor PD, Coen CW 2009 Maternal obesity induced by diet in rats permanently influences central processes regulating food intake in offspring. PLoS ONE 4:e5870

34. Ozanne SE, Lewis R, Jennings BJ, Hales CN 2004 Early programming of weight gain in mice prevents the induction of obesity by a highly palatable diet. Clin Sci (Lond) 106:141-145

35. Martin-Gronert MS, Ozanne SE 2005 Programming of appetite and type 2 diabetes. Early Hum Dev 81:981-988

36. Ahima RS, Prabakaran D, Flier JS 1998 Postnatal leptin surge and regulation of circadian rhythm of leptin by feeding. Implications for energy homeostasis and neuroendocrine function. J Clin Invest 101:1020-1027

37. Bouret SG, Draper SJ, Simerly RB 2004 Trophic action of leptin on hypothalamic neurons that regulate feeding. Science 304:108-110 